\title{
Geroprotectors as a novel therapeutic strategy for COPD, an accelerating aging disease
}

This article was published in the following Dove Press journal: International Journal of COPD

20 September 2012

Number of times this article has been viewed

\section{Kazuhiro Ito \\ Thomas Colley \\ Nicolas Mercado}

Airways Disease Section, National Heart and Lung Institute, Imperial College London, London, United Kingdom
Correspondence: Kazuhiro Ito National Heart and Lung Institute, Imperial College School of Medicine, Dovehouse St, London SW3 6LY, UK Tel +44207382 8I2I

Fax +44 2073518126

Email k.ito@imperial.ac.uk
Abstract: Chronic obstructive pulmonary disease (COPD) progresses very slowly and the majority of patients are therefore elderly. COPD is characterized by an abnormal persistent inflammatory response to noxious environmental stimuli and there are increasing evidences for a close relationship between premature aging and chronic inflammatory diseases. Thus, COPD is considered to be a disease of an accelerating aging. In this review, we collected the evidence for roles of aging on pathogenesis of COPD and considered future therapeutic strategy for COPD based on this senescence hypothesis. Since calorie restriction has been proved to extend lifespan, many efforts were made to clarify the molecular mechanism of aging. Aging is defined as the progressive decline of homeostasis that occurs after the reproductive phase of life is complete, leading to an increasing risk of disease or death due to impaired DNA repair after damage by oxidative stress or telomere shortening as a result of repeated cell division. During aging, pulmonary function progressively deteriorates; innate immunity is impaired and pulmonary inflammation increases, accompanied by structural changes, such as an enlargement of airspaces. Noxious environmental gases, such as cigarette smoke, may worsen these aging-related events in the lung or accelerate aging of the lung due to reduction in anti-aging molecules and/or stimulation of aging molecules. Aging signaling are complex but conserved in divert species, such as worm, fruit fry, rodent and humans. Especially the insulin like growth factor (IGF-1) signaling was well documented. Geroprotectors are therapeutics that affect the root cause of aging and age-related diseases, and thus prolong the life-span of animals. Most of geroprotectors such as melatonin, metformin, rapamycin and resveratrol are anti-oxidant or anti-aging molecule regulators. Therefore, geroprotection for the lung might be an attractive approach for the treatment of COPD by preventing premature aging of lung.

Keywords: premature aging, COPD, lung function, oxidative stress, sirtuin, geroprotector

\section{Introduction}

Globally, life expectancy is projected to increase from 68 years in 2005-2010 to 81 years in 2095-2100 according to the 2010 Revision of World Population Prospects, the official United Nation Population Projects (3rd May 2011). ${ }^{1}$ This is 35 years longer than that at beginning of the 20th century ( 46 years). Therefore, an increase in incidence of age-associated diseases such as Alzheimer's disease, cataract, rheumatoid arthritis, osteoporosis and cardiovascular disease will have a profound public health impact. Aging is a complex, universal condition leading to the functional decline of all cells and organisms, and to major global public health problems.

Chronic obstructive pulmonary disease (COPD) is one of the well-known age-associated diseases and a major and increasing global health problem with 
enormous amount of expenditure of indirect/direct health care costs. ${ }^{2,3}$ There is still a fundamental lack of knowledge about the cellular, molecular and genetic causes of COPD. Therefore, current therapies are inadequate and no treatments reduce disease progression or mortality. The pathological characteristics of COPD are chronic inflammation of peripheral and central airways, an increase in mucus producing cells and destruction of the lung parenchyma (emphysema). ${ }^{4}$ Airflow limitation measured by reduced forced expiratory volume in 1 second $\left(\mathrm{FEV}_{1}\right)$ progresses very slowly over several decades, and therefore most patients with symptomatic COPD are in late middle age or elderly. Thus, the incidence of COPD increases with age, suggesting an intimate relationship between the pathogenesis of COPD and aging. ${ }^{5}$

\section{COPD as an accelerating aging disease}

As the prevalence is reported to be two to three times higher in the elderly (persons over 60 years of age), therefore, COPD is known as an aging associated disease. The evidence for the role of accelerated aging in COPD progression is growing and senescence is one of possible molecular pathways for development of COPD. ${ }^{6}$

\section{Physiological or molecular change with aging}

The well-known epidemiological studies by Fletcher and Peto demonstrated an accelerated decline in lung function with time, with a loss of $20 \mathrm{~mL}$ per year, in healthy subjects with aging 7 as well as COPD. The decline of lung function in COPD with aging were also confirmed time to time and the results were recently summarized. ${ }^{8}$ In addition to the lung function decline with age, a dilatation of alveoli with an enlargement of airspaces and a decrease in gas exchange surface area with a loss of supporting tissue for peripheral airways were seen and called "senile emphysema". 9 This results in increased residual volume and functional residual capacity due to decreased static elastic recoils of the lung. Although the total lung capacity remains constant, vital capacity is reduced and functional residual capacity is increased with aging. ${ }^{10}$ Expiratory flows decrease with a characteristic alteration in the flow-volume curve suggesting small airway disease. Furthermore, respiratory muscle strength is also decreased with aging. ${ }^{11}$

It is also reported that the immune system ( $T$ cell and B cell) is impaired with aging, which is called immunosenescence. ${ }^{12}$ This results in an increased susceptibility to infection by bacteria and virus. However, the number of neutrophils in the lower respiratory tract of healthy elderly individuals is increased ${ }^{13}$ with an increased release of neutrophil elastase. This could contribute to the loss of elastic recoil and elastin fibers in the aging lung, resulting in deterioration of lung function.

Aging is a complex, heterogeneous, and multifactorial phenomenon, which is the consequence of multiple interactions between genes and environment. Senescence or aging is defined as the progressive decline of homeostasis that occurs after the reproductive phase of life is complete, leading to an increasing risk of disease or death. Underlying the aging process is a lifelong, bottom-up accumulation of molecular damage. Kirkwood also hypothesized that inflammatory and anti-inflammatory factors can play a part in shaping the outcomes of the aging process ${ }^{14}$ because cellular defects often cause inflammatory reactions, which can themselves exacerbate existing damage. Thus, aging is also considered as an inflammatory event. At molecular level, aging is the results of failure of reactive oxygen species (ROS) elimination, failure of repair of damaged DNA and telomere shortening as shown below.

Harman demonstrated that aging, senescence or agerelated changes is accelerated under the influence of oxidative stress (reactive oxygen species: ROS), formed during normal oxygen metabolism. ${ }^{15}$ This hypothesis is called "the free radical theory of aging" and has later been extensively supported by numerous in vivo and in vitro studies. This oxidative stress causes DNA damage and increases risk of cancer. Thus, the capacity for DNA repair may be an important determinant of the rate of aging at the cell and molecular level as Promislow reported a general relationship between longevity and DNA repair. ${ }^{16}$ The molecules responsible for DNA repair are DNA-dependent protein kinase (DNA-PK) and Ku86 (or Ku80). DNA-PK KO mice showed telomere shortening and intestinal atrophy, which are seen as aging phenotypes. Ku86 KO mice also showed the early onset of age-specific changes characteristic of senescence in mice. ${ }^{17}$

Increased production of oxygen-derived free radicals and reduced anti-oxidant capacity seen in aging are a primary driving force for inflammaging and redox-sensitive transcriptional factors, such as activator protein(AP)-1 and nuclear factor- $\kappa \mathrm{B}(\mathrm{NF}-\kappa \mathrm{B})$, which switch on multiple genes encoding pro-inflammatory molecules. ${ }^{18}$ Especially, increased NF- $\kappa \mathrm{B}$ activity during aging is due to hyperphosphorylation of I $\mathrm{B} \beta$ (inhibitory kappa B alpha). STAT3 and STAT 5, which are downstream of IL-6 signaling, were upregulated in T-cells from elderly subjects. ${ }^{19}$ As the results, increased levels of interleukin(IL)-1 $\beta$, IL-6, IL-8, IL-18, IL-1 ra and tumor 
necrosis factor- $\alpha$ (TNF $\alpha)$ were found in plasma, serum and mononuclear blood cell culture from elderly subjects. ${ }^{20,21}$ Redox-sensitive Cyclo-oxygenase (COX), an enzyme responsible for prostaglandin (PG) synthesis, is increased with aging. This PG synthesis pathway contributes to ROS accumulation during aging in a vicious circle.

In many human somatic tissues and cells such as fibroblasts, there is a decline in cellular division capacity with age or a limited division potential before undergoing so-called "replicative senescence." This appears to be linked to the fact that the telomeres, which protect the ends of chromosomes, get progressively shorter as cells divide. Oxidative stress has been found to have an even bigger effect on the rate of telomere loss, ${ }^{22}$ and telomere shortening is greatly accelerated (or slowed) in cells with increased (or reduced) levels of oxidative stress.

In the last decade, a lot of anti-aging molecules have been identified and the dysfunction and reduction of antiaging molecules are one of the causes of progressive aging. Sirtuins are well documented anti-aging molecules. Seven molecules have been identified in the human sirtuin family (SIRT1-SIRT7) and they are known to be NAD ${ }^{+}$dependent histone/protein deacetylases which are involved in gene expression, cell cycle regulation, apoptosis, metabolism, DNA repair and senescence. ${ }^{23,24}$ Especially, SIRT6 KO mice are reported to show aging phenotype by chromatin instability. ${ }^{25}$ As well as sirtuins (Type III HDAC), HDAC2 (a type I HDAC) is also reported to be an anti-aging molecule as knock-down of HDAC2 induces cellular senescence by enhancing p53-dependent trans-repression and trans-activation of a subset of target genes. ${ }^{26}$ FOXO transcription factor belongs to the large Forkhead family of proteins, a family of transcriptional regulators characterized by a conserved DNA-binding domain termed the 'forkhead box'. ${ }^{27}$ They are important transcriptional factors for DNA repair and production of anti-oxidants, such as Mn SOD and catalase. Recently, genetic ablation of FoxO3 was reported to lead to pulmonary emphysema and exaggerated inflammatory response in lungs of mice exposed to cigarette smoke. ${ }^{28}$ Targeted disruption of FoxO3 also resulted in down-regulation of antioxidant genes in mouse lungs in response to cigarette smoke exposure. Thus, FoxO3 plays a pivotal role in regulation of lung inflammatory response and antioxidant genes.

Homozygous mutant klotho $\left(K L^{-/}\right)$mice exhibit premature aging with a short life span and develop air space enlargement as well as some other aging phenotypes, such as arteriosclerosis, osteoporosis, skin atrophy, and ectopic calcifications. ${ }^{29}$ Fractal analysis suggested that the enlarged alveoli were homogenous, a result compatible with aged lung, but not with emphysema. ${ }^{30}$ The secreted Klotho protein can regulate multiple growth factor signaling pathways, including insulin/IGF-1 and Wnt, and the activity of multiple ion channels. Senescence marker protein-30 (SMP30), a 34-kD protein originally identified from the rat liver, is a novel molecule that decreases with age in an androgen-independent manner. The SMP30 knockout (SMP30Y/-) mouse has shorter life span and also developed senile lung with agerelated airspace enlargement and enhanced susceptibility to harmful stimuli. ${ }^{31}$ Cigarette smoke exposure generates marked airspace enlargement with significant parenchymal destruction in the SMP30Y/- mice. ${ }^{32}$ SMP30 was recently identified as a key enzyme (gluconolactonase) involved in the production of vitamin $\mathrm{C}^{33}$ and complete depletion of Vitamin C causes development of emphysema.

\section{Evidences of COPD to be an accelerating aging disease}

The classical epidemiological studies of Fletcher and Peto demonstrated that death and disability from COPD were related to an accelerated decline in lung function with time, with a loss of 50-100 $\mathrm{mL}$ in forced expiratory volume in 1 second $\left(\mathrm{FEV}_{1}\right)$ per year, and the decline was much quicker than normal aged lung in non-smokers and smokers.? Recently, Vestbo and colleagues demonstrated that the mean decrease in $\mathrm{FEV}_{1}$ per year in COPD patients was lower than in the Fletcher and Peto study. ${ }^{34}$ This might be one of the evidences underlying the accelerated lung aging process resulting from a failure of lung maintenance and repair due to significant and sustained lung injury by exposed noxious gases such as cigarette smoke. Functionally, vital capacity and respiratory muscle strength were reduced in COPD as well as with aging. ${ }^{10,11}$ Although air space enlargement was also observed in aged lung (senile lung), ${ }^{9}$ Fukuchi mentioned that aging dependent airway enlargement was different from emphysema in COPD. ${ }^{30}$ Premature aging might not be the direct cause of emphysema, but enhance the susceptibility of the lung to extrinsic insults including tobacco smoke from the evidence in anti-aging molecules (Klotho or SM30) deficient mice. ${ }^{30}$ Patel et al reported a good correlation between COPD and skin wrinkle, and this age-dependent loss of elastin fibers in lung is similar to the loss of skin elasticity and wrinkling of the skin that occurs with age. ${ }^{35}$ Aoshiba and Nagai reported that pulmonary emphysematous lesions appeared to be a dynamic phenomenon that involved not only the gradual loss of alveolar structure but also apoptosis, cellular proliferation, and cellular senescence. ${ }^{36}$ They mentioned 
that cellular proliferation compensated for increased alveolar cell apoptosis in patients with COPD, and this caused accelerating alveolar cell senescence, thereby preventing cellular proliferation and tipping the balance toward apoptosis. This, in turn, promotes the formation of emphysematous lesions.

In addition, cellular senescence is believed to induce inflammation or immuno-modulation in COPD. Lymphocyte senescence may induce an autoimmune reaction, a reduction in the adaptive immune response and possibly an increase susceptibility to infection. Particularly, lymphocytes may age more rapidly in the lungs of patients with COPD. ${ }^{36}$ There is an age-dependent decline in naïve $\mathrm{T}$ cells with oligoclonal expansion of CD8(+) CD28(null) T cells from chronic antigenic stimulation. ${ }^{37}$ The increase in CD8(+) CD28 (null) $\mathrm{T}$ regulatory cells inhibits antigen-specific $\mathrm{CD} 4(+) \mathrm{T}$ cell responses, leading to a decline in adaptive immune response. To compensate for the decline in the adaptive immune function there is a paradoxical up-regulation of innate immune system resulting in a proinflammatory state. The dysregulated adaptive immune system with activated innate immune responses seen with aging results in recruitment and retention of neutrophils, macrophages, and CD4(+) and CD8(+) T cells in the lungs of smokers with COPD. Once the inflammation is triggered, there is a self-perpetuating cascade of inflammation and lung parenchymal damage. ${ }^{37}$ Clara cells may also age more rapidly in the lungs of patients with COPD and Clara cell senescence may impair airway regeneration as well as sustain airway inflammation. ${ }^{36}$ Tsuji and colleagues demonstrated that alveolar cell senescence exacerbated pulmonary inflammation in patients with COPD. ${ }^{38}$ The lung tissue of the COPD patients contained higher percentages of proinflammatory senescent type II cells that co-expressed p16(INK4a) and phosphorylated NF- $\kappa \mathrm{B}$ than the tissue from asymptomatic smokers and asymptomatic non-smokers.

As suggested in "the free radical theory of aging" by Harman, ROS accounts for progressive deleterious changes called aging or senescence. ${ }^{15}$ There is accumulating evidence that oxidative stress plays an important role in pathogenesis of COPD, ${ }^{39}$ with increased expression of oxidative stress markers in patients with COPD both systemically and in disease lung. DNA damage is induced by oxidative stress and cigarette smoke and these are risk factors for carcinogenesis. In fact, patients with COPD have an increased risk of lung cancer. ${ }^{40,41}$ This suggests that cellular senescence could also explain the significantly increased rate of lung cancers in emphysematous patients by DNA damage. Anti-oxidant enzyme and activity are also decreased in COPD as seen in aging. ${ }^{42}$ SOD enzyme activity is reported to be lower in chronic healthy smokers and in stable COPD patients than in healthy adults. ${ }^{43}$ Furthermore, ferric reducing antioxidant power (FRAP) was lower in COPD patients and it had a positive correlation with the severity of airways obstruction ( $\mathrm{FEV}_{1} \%$ predicted). ${ }^{42}$ Anti-oxidant transcription factor, Nrf2, was also down-regulated in COPD. ${ }^{44}$

Furthermore, expressions of anti-aging molecules are reduced in COPD. We already reported that SIRT1 was selectively reduced in lung tissue and PBMCs from COPD ${ }^{45}$ in agreement with a recent report. ${ }^{46} \mathrm{We}$ also showed moderate reduction of SIRT6 expression in COPD lung. ${ }^{45}$ SIRT6 is a nuclear, chromatin-associated protein that promotes resistance to DNA damage and SIRT6 loss led to abnormalities in mice that overlapped with aging-associated degenerative processes. $^{25}$ It is unknown whether SIRT6-deficient mice develop emphysema or not (with or without smoke exposure), and further studies are required. We also have shown that HDAC2 activity and expression were markedly reduced in COPD in peripheral lung tissue and alveolar macrophages, especially in more severe disease and that this reduction was involved in enhancing inflammation and corticosteroid insensitivity. ${ }^{47,48}$ Furthermore, preliminary studies have found that Klotho and SMP-30 levels were decreased in COPD lung (unpublished data).

In addition, there are evidences that COPD lungs have shortened telomeres as compared with age-matched nonsmokers' lungs. Telomere length was recently demonstrated to be significantly shorter in the patients with emphysema than in the asymptomatic non-smokers that in alveolar type II cells and endothelial cells, ${ }^{49}$ circulating leukocytes, ${ }^{50}$ PBMCs $^{51}$ and fibroblasts. ${ }^{52}$

\section{Aging signaling}

Although the underlying mechanisms of aging or longevity are not fully understood, it is known that disruption of the insulin/insulin-like growth factor I (IGF-I) signaling cascade can significantly extend life span in diverse species, including yeast, worms, fruit flies, and rodents. ${ }^{53,54} \mathrm{IGF}-\mathrm{I}$ is a potent anabolic hormone that increases cellular metabolism, enhances the function of numerous tissues, and participates in glucose homeostasis. The long-lived mutants showed reduced insulin signaling and IGF-I plasma levels, and enhanced sensitivity to insulin as well as reduced oxidative damage of macromolecules and increased stress resistance. This fundamental mechanism of aging may be evolutionarily conserved from yeast to mammals (Figure 1).

The involvement of the insulin/IGF-I-signaling pathway to aging or longevity was first demonstrated in invertebrates. 


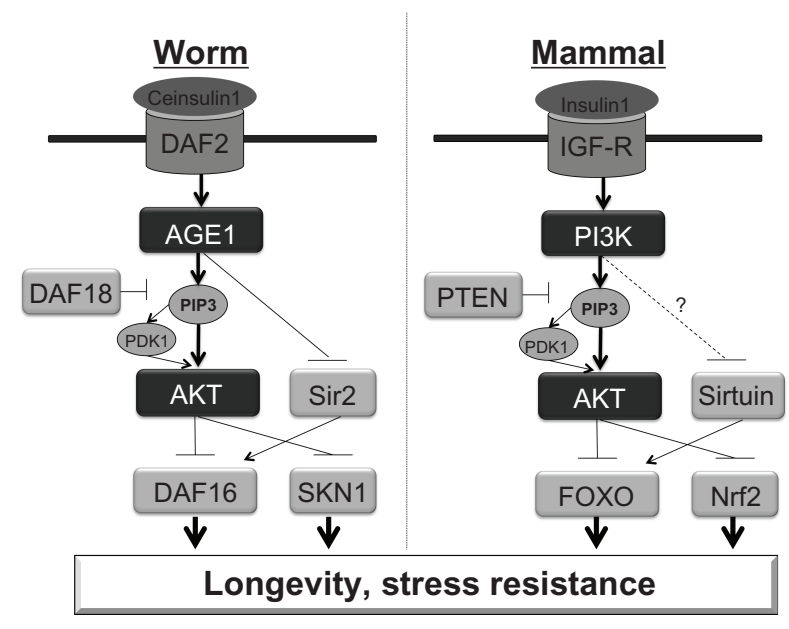

Figure I Similarity of Aging signaling between Caenorhabditis elegans and mammals. (A) Caenorhabditis elegans (C. elegans), (B) Mammals.

Notes: In C. elegance, DAFI6 and SKNI induce anti-oxidant enzymes, leading longevity and stress resistance. However, Ce-insulin I signaling inactivates DAFI 6 and SKNI. DAFI 8 is a phosphatase to convert PIP3 to PIP2 to prevent AGEI signaling. In mammals, IGF-R is equivalent to DAF2 in worm, PI3K for AGEI, Sirtuin for Sir2, FOXO for DAFI6, Nrf2 for SKNI.

In Caenorhabditis elegans (C. elegans), daf-2, age-1, and daf-16 mutants showed longer life span. ${ }^{55,56}$ In addition to the overall life span extension, worms with mutation of the daf-2 pathway exhibited increased resistance to oxidative stress,${ }^{57}$ hypoxia ${ }^{58}$ and bacterial pathogens. ${ }^{59}$ Daf-2 mutants expressed high levels of antioxidant enzymes such as catalase (the gene $c t l-1$ ) and superoxide dismutase (SOD), and the age- 1 mutation partially prevented the age-associated decrease of catalase in adults of $C$. elegans.

Although there is no exact counterpart for those genes in most mammals or humans, similar molecules are involved in this conservative aging cascade. The gene $d a f-2$ encodes an insulin/IGF-I receptor-like protein which is possibly the common ancestor of human insulin receptor, human IGF-I receptor (IGF-IR), and the human insulin receptorrelated receptor. Age-1 gene encodes a protein similar to the mammalian p1 10 catalytic subunit of PI3K. The dauer formation protein (DAF)-16 has similarity to a family of mammalian forkhead transcriptor factors (FOXO). A null mutation in $d a f-16$ suppressed the phenotype of $d a f-2$ and age-1. As well as DAF16, SNK-1 is also involved in expression of anti-oxidant proteins in C. elegans, and this is $\mathrm{Nrf2}$ (Nuclear factor (erythroid-derived 2)-like 2) human homolog. ${ }^{60}$ DAF18 is an anti-aging molecule in worms and this encodes PTEN (Phosphatase and tensin homolog), which dephosphorylates Phosphatidylinositol (3,4,5)-triphosphate (PIP3) phosphorylated by PI3K. Sir2, a sirtuin, is also anti-aging molecule in worms, and encodes sirtuin human homolog (Figure 1).
A decrease in insulin/IGF-I signaling has also been shown to extend longevity in mice. Analysis of various transgenic and knockout rodent models, characterized by shortening or extension of the life span. ${ }^{61}$ In humans, insulin sensitivity normally declines during aging, and insulin resistance is an important risk factor associated with hypertension, atherosclerosis and obesity, which are affecting morbidity, disability, and mortality among the elderly. Polymorphic variants of IGF-I receptor (IGF-IR) and phosphatidylinositol 3-kinase (PI3K) genes affect IGF-I plasma levels and human longevity. ${ }^{62}$

Oxidative stress shares the same signaling with IGF-I. There are a lot of evidence that oxidative stress stimulated PI3K signaling, and chronic or high level of oxidative stress exposure impaired FOXO and Nrf2 responses ${ }^{63}$ via defects of $\mathrm{HDAC}^{64}$ and sirtuins ${ }^{45}$ (Figure 2). AMPK is activated under oxidative stress, but chronic exposure of oxidative stress reduces AMPK activity in lung epithelial cells (data not shown). Further studies are required to clarify the mechanism of this defect. mTOR (TORC1) is also activated as a consequence of PI3K activation.

\section{Potential geroprotectors}

Geroprotectors are therapeutics that affect the root cause of aging and age-related diseases, and thus slow down the aging process. ${ }^{65}$ These have a potential to improve age-associated disease such as COPD. Calorie restriction is the best researched

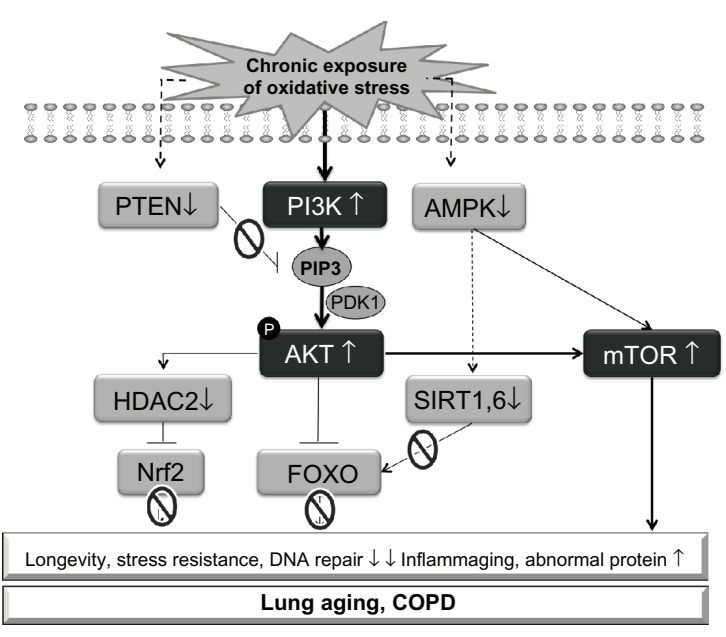

Figure 2 Schematic illustration of putative aging signaling in COPD under oxidative stress.

Notes: Accumulation of endogenous reactive oxygen species (ROS) activates PI3K signaling, leading dysfunction of FOXO and Nrf2 via defect of HDAC2 and sirtuins. PTEN reduction amplifies PI3K signaling, and AMPK inactivation also contributes to reduction of sirtuin activity. At the same time, mTOR is activated as downstream molecule of PI3K. Consequently, the level of stress resistance and DNA repair ability are reduced, inflammaging is amplified and abnormal proteins are accumulated, causing accelerating aging and progress of COPD. 
intervention in aging in diverse species from yeast to primate. Most of geroprotectors might mimic calorie restriction. Greater understanding of the molecular mechanisms of aging has revealed several novel targets for anti-aging drugs/geroprotectors although the information about the effects of those drugs in the respiratory system is still limited (Table 1).

\section{Metformin}

Metformin (N,N-dimethylbiguanide) is an anti-glycemic, biguanide class drug used in the treatment of diabetes mellitus and polycystic ovarian syndrome. Several studies have shown that metformin can slow down the rate of aging, and decrease glucose, insulin and IGF-1 level. Thus Metformin has been described as a geroprotector. ${ }^{66}$

Anisimov and colleagues recently showed that metformin treatment increased mean life span by up to $14 \%$ and postponed tumors in female SHR mice when treated early in life. ${ }^{67}$ They also showed that metformin $(100 \mathrm{mg} / \mathrm{kg})$ increased the mean life span by $8 \%$ and maximum life span by $13.1 \%$ of HER-2/neu mice. ${ }^{68}$ In addition, metformin increased the

Table I Potential geroprotectors and their mode of actions

\begin{tabular}{|c|c|c|c|}
\hline Drug & Mode of action & $\begin{array}{l}\text { Life-span } \\
\text { extension }\end{array}$ & Others \\
\hline Metformin & $\begin{array}{l}\text { AMPK activation } \\
\text { SIRTI activation } \\
\text { mTOR inhibition } \\
\text { Anti-oxidant }\end{array}$ & $\begin{array}{l}\text { Yeast } \\
\text { C. elegans, } \\
\text { Drosophila } \\
\text { Mice } \\
\text { Rat }\end{array}$ & \\
\hline Melatonin & $\begin{array}{l}\text { Hormone } \\
\text { Anti-oxidant } \\
\text { Anti-inflammatory }\end{array}$ & $\begin{array}{l}\text { C. elegans, } \\
\text { Drosophila } \\
\text { Mice } \\
\text { Rat }\end{array}$ & $\begin{array}{l}\text { 8-Isoprostane } \downarrow \\
\text { Improved dysnea } \\
\text { in COPD }\end{array}$ \\
\hline Rapamycin & mTOR inhibition & $\begin{array}{l}\text { Yeast, } \\
\text { C. elegans, } \\
\text { Drosophila } \\
\text { Mice }\end{array}$ & \\
\hline Resveratrol & $\begin{array}{l}\text { Anti-oxidant } \\
\text { SIRT activation } \\
\text { AMPK activation } \\
\text { PI3K inhibition }\end{array}$ & $\begin{array}{l}\text { Yeast, } \\
\text { C. elegans, } \\
\text { Drosophila } \\
\text { Fish } \\
\text { Mice }\end{array}$ & $\begin{array}{l}\text { Inhibition of } \\
\text { cytokine release } \\
\text { in alveolar } \\
\text { macrophages } \\
\text { from COPD }\end{array}$ \\
\hline Lower dose & PI3K $\delta$ inhibition & & Low dose \\
\hline Theophylline & PARP inhibition & & $\begin{array}{l}\text { theophylline } \\
\text { improved lung } \\
\text { function in COPD }\end{array}$ \\
\hline SRT2I 72 & SIRTI activation & & $\begin{array}{l}\text { Inhibition of MMP9, } \\
\text { IL-8, neutrophilia } \\
\text { in smoking mice }\end{array}$ \\
\hline Sulforaphane & Nrf2 activation & Drosophila & $\begin{array}{l}\text { Reversed steroid } \\
\text { insensitivity in } \\
\text { alveolar macrophage } \\
\text { from COPD }\end{array}$ \\
\hline
\end{tabular}

mean life span by $8 \%$, maximum life span by $16 \%$ in female FVB/N mice. The mechanisms behind the geroprotective effect of metformin are less established, but several potential mechanisms were reported. ${ }^{66}$

AMPK ( $5^{\prime}$ AMP-activated protein kinase ) is a serine/ threonine protein kinase that belongs to the energy sensing kinase family, which plays a role in cellular energy homeostasis. ${ }^{69}$ In general, activation of AMPK acts to maintain cellular energy stores, switching on catabolic pathways that produce ATP, mostly by enhancing oxidative metabolism and mitochondrial biogenesis, while switching off anabolic pathways that consume ATP. Metformin has been shown to activate AMPK in several cells such as skeletal muscle, heart, endothelial and hepatocytes, leading to reduced glucose production in the liver and reduced insulin resistance in the muscle. ${ }^{66}$ In addition to cellular energy sensing function, AMPK enhances SIRT1 activity by increasing cellular NAD+ levels, ${ }^{70}$ resulting in the deacetylation and modulation of the activity of downstream SIRT1 targets that include the peroxisome proliferator-activated receptor-gamma coactivator 1alpha and the forkhead box $\mathrm{O} 1$ (FOXO1) and $\mathrm{O} 3$ (FOXO3a) transcription factors. AMPK also phosphorylates and activates FOXO (DAF16) directly in worms, resulting in an increase of anti-oxidative stress capacity. SIRT1 deacetylates FOXO proteins in response to oxidative stress, and this could result in their activation. Metformin is also reported to inhibit mTOR signaling ${ }^{71}$ via AMPK activation, and mTOR inhibition activates sirtuin. Thus, AMPK activation by metformin affects sirtuin-FOXO axis or sirtuin-mTOR signalling, resulting in extension of life span, and it possibly improves lung function and inhibits airway inflammation in the lung.

However, metformin failed to activate AMPK in lung tissue because lungs have a very low expression of OCT1, a receptor responsible for metformin uptake in cells. ${ }^{72}$ Therefore, metformin unlikely affects lung epithelial cells directly, but possibly affects other resident cells such as alveolar macrophages and immune cells. Although patients with diabetes mellitus are not at increased risk for the development of lung cancer, the use of metformin type antidiabetes drugs considerably decreased the risk. ${ }^{73}$ As diabetes mellitus and metabolic syndrome are common in patients with COPD, ${ }^{74}$ metformin might affect comorbidity of COPD and improve symptom systemically.

\section{Melatonin}

Melatonin, $\mathrm{N}$-acetyl-5-methoxytryptamine, is a naturally occurring compound found in animals, plants, and microbes. The pineal indole hormone melatonin is involved 
in the circadian rhythms (the sleep-wake cycle) of several biological functions through activation of melatonin receptors. Besides its function, melatonin is also known to exert a powerful antioxidant activity. Melatonin is a direct scavenger of $\mathrm{OH}, \mathrm{O}_{2}^{-}$, and $\mathrm{NO}^{75}$

The effect of melatonin on the life-span of mice, rats and fruit flies has been studied using various approaches. Izmaylov and Obukhora demonstrated that melatonin extended life span of Drosophila melanogaster possibly due to an anti-oxidant mechanism. ${ }^{65}$ Melatonin also increased life-span of female CBA mice. ${ }^{76}$ Furthermore, prolonged life-span by long-term administration of melatonin have been observed in SHR, ${ }^{77}$ SAM and transgenic HER-2/neu mice. Sharman and colleagues reported that melatonin treatment reversed the change in expression of 13 genes in the cerebral cortex of elderly $\mathrm{B} 6 \mathrm{C} 3 \mathrm{~F} 1$ male compared with younger mice. ${ }^{78}$ Furthermore, melatonin treatment also increased survival of male and female rats. However at the same time, melatonin increased tumor incidence in the mice. Melatonin alone turned out neither toxic nor mutagenic in the Ames test but revealed clastogenic activity at high concentration in the COMET assay. ${ }^{79}$ On the other hand, melatonin inhibited mutagenesis and clastogenic effects of a number of indirect chemical mutagens. The genotox mechanism should be explored more before conducting a long term clinical trial.

In bronchial asthma and COPD, melatonin level in serum was decreased during exacerbation with an increase in oxidative stress and a decrease in anti-oxidant enzymes. ${ }^{80}$ Melatonin has been tested for COPD. In a randomized, double-blind, placebo-controlled study on the effects of melatonin in COPD,${ }^{81}$ thirty-six consecutive patients with clinically stable moderate to very severe COPD (30 men; mean $\pm \mathrm{SD}=66.6 \pm 7.8 \mathrm{y}$ ) were recruited and treated with $3 \mathrm{mg}$ melatonin $(\mathrm{N}=18)$ or placebo for 3 months. Oxidative stress was evaluated by 8-isoprostane levels in exhaled breath condensate at baseline and after one, two and three months of treatment. In addition, IL-8 levels in exhaled breath condensate, dyspnea severity (Medical Research Council scale), lung function (spirometry), and functional exercise capacity (six min walk test) were compared at baseline and after treatment. Patients receiving melatonin showed a decrease in 8-isoprostane with significant improvement of dyspnea, although there were no significant changes in lung function or exercise capacity. The patients given melatonin did not show an increase in IL-8 $(P=0.03)$ over 3 months. Further studies are necessary to determine the potential role for melatonin in the long-term management of these patients.
As well as its anti-oxidant mechanism, recently melatonin is shown to activate SIRT1 in primary neurons of young animals, as well as in aged neurons of a murine model of senescence. Rodella et al demonstrated that SIRT1 was decreased in apolipoprotein E (APOE)-deficient mice with age, and melatonin treatment clearly restored the SIRT1 level. ${ }^{82}$ SIRT1-p53-eNOS axis is one of the important markers of advanced vascular dysfunctions linked to aging and melatonin could reverse the defect. Melatonin was also reported to suppress production of IL- $8^{83}$ and matrix metalloproteinase- $9 .{ }^{84}$

\section{Resveratrol}

Resveratrol (3,4',5-trihydroxystilbene) the plant polyphenol, is found in various plants, including grapes, berries and peanuts. It is also present in wines, especially red wines..$^{85}$ Studies showed that resveratrol extended the life-span of yeast, worms, flies, fish and mice. Resveratrol appears to mediate these effects partly by activating SIRT1, a deacetylase enzyme. ${ }^{86}$ Resveratrol is also reported to be a powerful anti-oxidant ${ }^{85}$ as well as a PI3K inhibitor. ${ }^{87}$ Recently, Dallaire and Marette demonstrated that resveratrol inhibited inducible nitric oxide synthase in skeletal muscle by AMPK activation rather than SIRT1 activation. ${ }^{88}$ As we described above, AMPK activator also leads to SIRT1 activation. Thus resveratrol affects AMPK-SIRT1 axis and showed anti-aging effects. In addition, there are a lot of evidences of anti-inflammatory effects of resveratrol in lung cells. ${ }^{89}$

\section{PI3K inhibitors}

In C. elegans, age-1 (human PI3K homolog) mutant showed longer life, suggesting that P13K inhibition extends life span. In fact, a pan PI3K inhibitor, LY294002 (2-(4-Morpholinyl)8-phenyl-4H-1-benzopyran-4-one) at higher concentrations significantly resulted in a small, but significant, increase in life-span..$^{90}$ It is also reported that LY294002 extended lifespan of D. melanogaster. ${ }^{91}$

We previously demonstrated that $\mathrm{PI} 3 \mathrm{~K} \delta$ was upregulated in peripheral lung of COPD and it is involved in corticosteroid resistance..$^{92}$ None of PI3K $\delta$ inhibitors is available in clinic, but theophylline is known to exert functional PI3K $\delta$ inhibition at lower dose. When low dose theophylline was used with steroid, it showed better efficacy in asthma and COPD than steroid alone. In the in vitro and in vivo studies, PI3K $\delta$ inhibition enhanced steroid action. ${ }^{92}$ Theophylline reversed defect of HDAC activity via PI3K $\delta$ inhibition. As HDAC2 is known as anti-aging molecule, theophylline is a kind of anti-aging agent. Theophylline is also reported to 
inhibit $\mathrm{NAD}^{+}$consumption by PARP-1 activation ${ }^{93}$ and may therefore restore SIRT1 activity reduced under oxidative stress.

\section{mTOR inhibitor}

Mammalian target of rapamycin (mTOR) is a serine/ threonine kinase in the phosphoinositide 3-kinase (PI3K)related kinase family. mTOR forms two distinct protein complexes including TORC1 and TORC2, with distinct cellular functions. TORC1 regulates translation initiation and elongation, ribosome biogenesis, cell-cycle progression, lipid synthesis, mitochondrial biogenesis and authophagy. ${ }^{94}$ Knockdown of mTOR by RNA interference has been shown to extend the life span of worm and fruit fly. mTOR phosphorylates insulin receptor substrate 1(IRS-1), causing insulin resistance by inhibition of insulin signalling. TORC1 also inhibits autophagy and accelerate protein synthesis. Therefore, inhibition of mTOR leads to geroprotection.

Rapamycin (Sirolimus) is an immunosuppressive agent used to prevent rejection in transplantation patients. This inhibits TORC1 and this inhibition extended the life span of yeast, C. elegance, Drosophila and mice. ${ }^{94}$ Very interestingly, the effect of mTOR inhibition is sex dependent, and rapamycin showed more moderate increase in life span in male rather than female in flies and mice. However, rapamycin showed immunosuppressive action by an anti-proliferative effect on clonal expansion of activated lymphocytes. Long term trial of rapamycin has not been conducted in COPD.

\section{SIRT activator}

Sirtuins are anti-aging molecules and control oxidative stress resistance, DNA repair and inflammation as described above. Sirtuin activation extended life span in worms by activation of autophagy ${ }^{95}$ and SIRT1 is required for the autophagic response to nutrient deprivation. In addition, SIRT1 negatively regulated MMP9 synthesis $^{45,96}$ and SIRT1 knockdown by RNA interference enhanced MMP9 synthesis and activation. In fact, SIRT1 mRNA and protein expression are reduced in peripheral lung and alveolar macrophages of patients with COPD.$^{45}$ Even more importantly (therapeutically), SIRT1 overexpression inhibited MMP9 expression stimulated by LPS in U937 cells.

As described as previous page, Resveratrol is known as a sirtuin activator although the molecular mechanism is controversial. ${ }^{97}$ Recently a SIRT1-specific activator that is
1000 more potent than resveratrol has been developed and examined as a possibile therapy for diabetics. ${ }^{98}$ SRT2 2172 is one of the potent sirtuin activators. In sub-chronic smoking mice, SIRT1 activity in lung was decreased but SRT2172 intra-nasal treatment reversed this reduction. ${ }^{45}$ Exercise tolerance was impaired and oxygen saturation, as well as $\mathrm{SPO}_{2}$ level, after exercise was lowered in the smoking mice, but SRT2172 treatment restored exercise tolerance and $\mathrm{SPO}_{2}$ level as we previously reported (Figure 3). ${ }^{45}$ Thus, SIRT1 activators are promising agents for the treatment of COPD in future.

\section{Nrf2 activator}

From the oxidative stress/aging theory and the fact that oxidative stress is a major risk factor of COPD, anti-oxidants are likely to be effective anti-aging and COPD drugs. Currently available antioxidants, such as $\mathrm{N}$-acetyl cysteine, are not very potent and may not sufficiently reduce oxidative stress in the lungs. Although some new anti-oxidants such as glutathione and superoxide dismutase analogs have been developed, novel and more effective antioxidants are required. Nuclear factor erythroid 2-related factor 2 (Nrf2) is a cap'n'collar family member redox-sensitive transcription factor that induces endogenous anti-oxidant molecules such as the phase II antioxidant genes, which includes glutathione peroxidase (GPx), glutathione-S-transferase (GST), and stress-response genes, such as heme oxygenase-1 (HO-1), confering cytoprotection against oxidative stress. ${ }^{63}$ Therefore this is a potential target to increase anti-oxidant activity.

As previously reported, $\mathrm{Nrf} 2$ function is impaired in COPD. For example, whole lung tissue and alveolar macrophages from emphysema patients were reported to show a decreased Nrf2 expression and anti-oxidant genes due to increased Keap1 and Bach1. Another study on lung homogenates from patients with COPD found that defective Nrf2 expression was due to decreased expression of its positive regulator DJ-1. We found that HDAC2 reduction by cigarette smoke exposure caused hyperacetylation of $\mathrm{Nrf} 2,{ }^{63}$ resulting in defect of Nrf2 induction. There are a lot of candidates as Nrf2 activators. ${ }^{99}$ Sulforaphane, which is extracted from broccoli, is reported as a Nrf2 activator. ${ }^{100}$ Malhotra and colleagues recently demonstrated that treatment with sulforaphane stimulated $\mathrm{Nrf} 2$, resulting in denitrosylation of HDAC2 and restoration of steroid sensitivity in alveolar macrophages from patients with COPD. Thus, sulforaphane, by activating Nrf2, is a novel therapy for reversing corticosteroid resistance in COPD and other corticosteroid-resistant inflammatory diseases. ${ }^{101}$ 

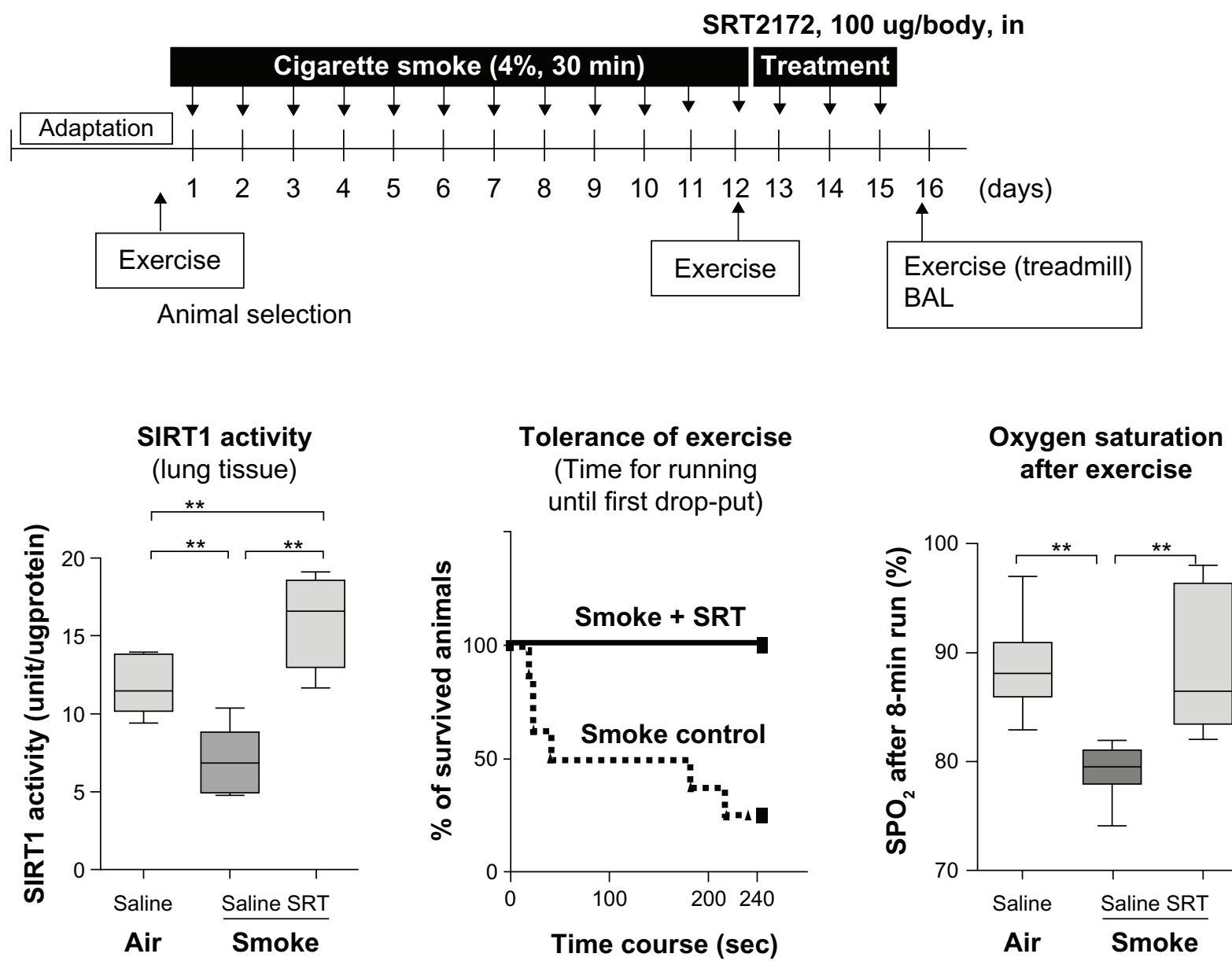

\section{after exercise}

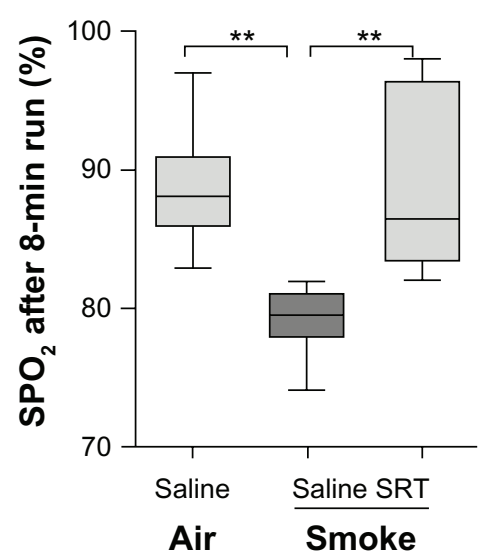

Figure 3 Effects of SRT2I72, a SIRTI activator, on SIRTI activity, Exercise tolerance and $\mathrm{SpO}_{2}$ reduction after exercise. A/J female mice were exposed to cigarette smoke (4\%) for 12 days. SRT2 I 72 ( $100 \mu \mathrm{g} /$ animal) or vehicle (PBS) was administered intra-nasally once daily for 3 days following exposure to the last cigarette. (A) SIRTI activity was determined in nuclear rich fraction of lung tissue. (B) Mice were placed on a treadmill and drop-out rate by exhaustion (when the mouse stopped running) during an 8 min run $(4 \mathrm{~m} / \mathrm{min}$ at first $4 \mathrm{~min}$, and then $6 \mathrm{~m} / \mathrm{min}$ for $4 \mathrm{~min}$ ) was determined. (C) SPO, level was measured by pulse oximeter at the thigh after an $8 \mathrm{~min}$ run.

Notes: $* * * *$ indicates $P<0.05, P<0.01 . \mathrm{n}=6-8$.

(C) Copyright 2009. Adapted with permission from Nakamaru Y, Vuppusetty C, Wada H, et al. A protein deacetylase SIRTI is a negative regulator of metalloproteinase-9. FASEB J. Sep 2009; 23(9):2810-2819.

\section{Conclusion and future directions}

COPD is one of the most prevalent chronic inflammatory diseases in elderly worldwide. Loss of working generation and disabilities associated with COPD should require urgent awareness by government, physicians and scientists, and new treatment strategy should be considered as current therapy is not useful to stop the progression of COPD. The role of accelerated aging in COPD progression is now strongly supported by numerous recent studies. In addition, aging signal cascade research has been expanded from worm and fruit fly to mammals or humans, and several molecules have been identified as the target of anti-aging drugs. Thus, geroprotection or anti-aging therapy will be the novel and attractive strategy to treat age associated inflammatory diseases or to increase quality of life in elderly patients. For this purpose, geroprotectors will be not used to extend life-span but used to prevent premature aging of the lung by exposure of oxidants. The information of effects of geroprotectors on lung aging or respiratory diseases is still limited and further investigations will be required to clarify whether those drugs are able to modify the course of COPD.

\section{Acknowledgments}

We regret that owing to space constraints we were not able to cite all the important original publications and apologies to those authors whose work we have not cited.

\section{Disclosure}

Kazuhiro Ito is currently an employee of RespiVert Ltd, and has on honorary contract with Imperial College. None of the authors has any financial relationship with a commercial entity that has an interest in the subject of this manuscript. 


\section{References}

1. United Nation. World Population to reach 10 billion by 2100 if Fertility in all Countries Converges to Replacement Level. UNITED NATIONS PRESS RELEASE. 3-5-2011. Ref Type: Abstract.

2. Buist AS, McBurnie MA, Vollmer WM, et al. International variation in the prevalence of COPD (the BOLD Study): a population-based prevalence study. Lancet. September 1, 2007;370(9589):741-750.

3. Menn P, Heinrich J, Huber RM, et al. Direct medical costs of COPD An excess cost approach based on two population-based studies. Respir Med. Apr 2012;106(4):540-548.

4. Hogg JC, Timens W. The pathology of chronic obstructive pulmonary disease. Anпи Rev Pathol. 2009;4:435-459.

5. Ito K, Barnes PJ. COPD as a disease of accelerated lung aging. Chest. Jan 2009;135(1):173-180.

6. Lee J, Sandford A, Man P, Sin DD. Is the aging process accelerated in chronic obstructive pulmonary disease? Curr Opin Pulm Med. Mar 2011;17(2):90-97.

7. Fletcher $\mathrm{C}$, Peto R. The natural history of chronic airflow obstruction. Br Med J. June 25, 1977;1(6077):1645-1648.

8. Tantucci C, Modina D. Lung function decline in COPD. Int J Chron Obstruct Pulmon Dis. 2012;7:95-99.

9. Janssens JP, Pache JC, Nicod LP. Physiological changes in respiratory function associated with ageing. Eur Respir J. Jan 1999;13(1): 197-205.

10. Chan ED, Welsh CH. Geriatric respiratory medicine. Chest. Dec 1998; 114(6):1704-1733.

11. Tolep K, Kelsen SG. Effect of aging on respiratory skeletal muscles. Clin Chest Med. Sep 1993;14(3):363-378.

12. Lee N, Shin MS, Kang I. T-cell biology in aging, with a focus on lung disease. J Gerontol A Biol Sci Med Sci. Mar 2012;67(3):254-263.

13. Meyer KC, Rosenthal NS, Soergel P, Peterson K. Neutrophils and low-grade inflammation in the seemingly normal aging human lung. Mech Ageing Dev. August 14, 1998;104(2):169-181.

14. Kirkwood TB. Understanding the odd science of aging. Cell. February 25, 2005;120(4):437-447.

15. Harman D. Free radical theory of aging: an update: increasing the functional life span. Ann N Y Acad Sci. May 2006;1067:10-21.

16. Promislow DE. DNA repair and the evolution of longevity: a critical analysis. J Theor Biol. October 7, 1994;170(3):291-300.

17. Vogel H, Lim DS, Karsenty G, Finegold M, Hasty P. Deletion of Ku86 causes early onset of senescence in mice. Proc Natl Acad Sci U S A. September 14, 1999;96(19):10770-10775.

18. Rahman I, Adcock IM. Oxidative stress and redox regulation of lung inflammation in COPD. Eur Respir J. Jul 2006;28(1):219-242.

19. Fulop T, Larbi A, Douziech N, Levesque I, Varin A, Herbein G. Cytokine receptor signalling and aging. Mech Ageing Dev. Jun 2006; 127(6):526-537.

20. Chung HY, Sung B, Jung KJ, Zou Y, Yu BP. The molecular inflammatory process in aging. Antioxid Redox Signal. Mar 2006;8(3-4):572-581.

21. Ito $\mathrm{K}$. Does lung aging have an impact on chronic obstructive pulmonary disease? J Organ Dysfunction. January 22, 2007;3(4):204-220.

22. von Zglinicki T. Oxidative stress shortens telomeres. Trends Biochem Sci. Jul 2002;27(7):339-344.

23. Grubisha O, Smith BC, Denu JM. Small molecule regulation of Sir2 protein deacetylases. FEBS J. Sep 2005;272(18):4607-4616.

24. Rahman S, Islam R. Mammalian Sirt1: insights on its biological functions. Cell Commun Signal. 2011;9:11.

25. Mostoslavsky R, Chua KF, Lombard DB, et al. Genomic instability and aging-like phenotype in the absence of mammalian SIRT6. Cell. January 27, 2006;124(2):315-329.

26. Harms KL, Chen X. Histone deacetylase 2 modulates p 53 transcriptional activities through regulation of p53-DNA binding activity. Cancer Res. April 1, 2007;67(7):3145-3152.

27. Kaestner KH, Knochel W, Martinez DE. Unified nomenclature for the winged helix/forkhead transcription factors. Genes Dev. January 15, 2000;14(2):142-146.
28. Hwang JW, Rajendrasozhan S, Yao H, et al. FOXO3 deficiency leads to increased susceptibility to cigarette smoke-induced inflammation, airspace enlargement, and chronic obstructive pulmonary disease. J Immunol. July 15, 2011;187(2):987-998.

29. Suga T, Kurabayashi M, Sando Y, et al. Disruption of the klotho gene causes pulmonary emphysema in mice. Defect in maintenance of pulmonary integrity during postnatal life. Am J Respir Cell Mol Biol. Jan 2000;22(1):26-33.

30. Fukuchi Y. The aging lung and chronic obstructive pulmonary disease: similarity and difference. Proc Am Thorac Soc. December 1, 2009;6(7): $570-572$.

31. Maruyama N, Ishigami A, Kuramoto M, et al. Senescence marker protein-30 knockout mouse as an aging model. Ann N Y Acad Sci. Jun 2004;1019:383-387.

32. Sato T, Seyama K, Sato Y, et al. Senescence marker protein-30 protects mice lungs from oxidative stress, aging, and smoking. Am J Respir Crit Care Med. September 1, 2006;174(5):530-537.

33. Koike K, Kondo Y, Sekiya M, et al. Complete lack of vitamin C intake generates pulmonary emphysema in senescence marker protein-30 knockout mice. Am J Physiol Lung Cell Mol Physiol. Jun 2010;298(6): L784-L792.

34. Vestbo J, Edwards LD, Scanlon PD, et al. Changes in forced expiratory volume in 1 second over time in COPD. N Engl J Med. September 29, 2011;365(13):1184-1192

35. Patel BD, Loo WJ, Tasker AD, et al. Smoking related COPD and facial wrinkling: is there a common susceptibility? Thorax. Jul 2006;61(7): 568-571.

36. Aoshiba K, Nagai A. Senescence hypothesis for the pathogenetic mechanism of chronic obstructive pulmonary disease. Proc Am Thorac Soc. December 1, 2009;6(7):596-601.

37. Sharma G, Hanania NA, Shim YM. The aging immune system and its relationship to the development of chronic obstructive pulmonary disease. Proc Am Thorac Soc. December 1, 2009;6(7):573-580.

38. Tsuji T, Aoshiba K, Nagai A. Alveolar cell senescence in patients with pulmonary emphysema. Am J Respir Crit Care Med. October 15, 2006; 174(8):886-893.

39. MacNee W. Oxidants/antioxidants and chronic obstructive pulmonary disease: pathogenesis to therapy. Novartis Found Symp. 2001;234: 169-185.

40. Sekine Y, Katsura H, Koh E, Hiroshima K, Fujisawa T. Early detection of COPD is important for lung cancer surveillance. Eur Respir $J$. May 2012;39(5):1230-1240.

41. de Torres JP, Marin JM, Casanova C, et al. Lung cancer in patients with chronic obstructive pulmonary disease - incidence and predicting factors. Am J Respir Crit Care Med. October 15, 2011;184(8): 913-919.

42. Nadeem A, Raj HG, Chhabra SK. Increased oxidative stress and altered levels of antioxidants in chronic obstructive pulmonary disease. Inflammation. Feb 2005;29(1):23-32.

43. Kirkil G, Hamdi MM, Seckin D, Sahin K, Kucuk O. Antioxidant effect of zinc picolinate in patients with chronic obstructive pulmonary disease. Respir Med. Jun 2008;102(6):840-844.

44. Malhotra D, Thimmulappa R, Navas-Acien A, et al. Decline in NRF2regulated antioxidants in chronic obstructive pulmonary disease lungs due to loss of its positive regulator, DJ-1. Am J Respir Crit Care Med. September 15, 2008;178(6):592-604.

45. Nakamaru Y, Vuppusetty C, Wada H, et al. A protein deacetylase SIRT1 is a negative regulator of metalloproteinase-9. FASEB J. Sep 2009; 23(9):2810-2819.

46. Rajendrasozhan S, Yang SR, Kinnula VL, Rahman I. SIRT1, an antiinflammatory and antiaging protein, is decreased in lungs of patients with chronic obstructive pulmonary disease. Am J Respir Crit Care Med. April 15, 2008;177(8):861-870.

47. Ito K, Ito M, Elliott WM, et al. Decreased histone deacetylase activity in chronic obstructive pulmonary disease. $N$ Engl J Med. May 12, 2005; 352(19):1967-1976. 
48. Ito K, Yamamura S, Essilfie-Quaye S, et al. Histone deacetylase 2-mediated deacetylation of the glucocorticoid receptor enables NF-kappaB suppression. J Exp Med. January 23, 2006;203(1):7-13.

49. Tsuji T, Aoshiba K, Nagai A. Alveolar cell senescence in patients with pulmonary emphysema. Am J Respir Crit Care Med. October 15, 2006; 174(8):886-893.

50. Savale L, Chaouat A, Bastuji-Garin S, et al. Shortened telomeres in circulating leukocytes of patients with chronic obstructive pulmonary disease. Am J Respir Crit Care Med. April 1, 2009;179(7):566-571.

51. Morla M, Busquets X, Pons J, Sauleda J, MacNee W, Agusti AG Telomere shortening in smokers with and without COPD. Eur Respir J. Mar 2006;27(3):525-528.

52. Muller KC, Welker L, Paasch K, et al. Lung fibroblasts from patients with emphysema show markers of senescence in vitro. Respir Res. 2006;7:32

53. Holzenberger M. Igf-I signaling and effects on longevity. Nestle Nutr Workshop Ser Pediatr Program. 2011;68:237-245.

54. Barbieri M, Bonafe M, Franceschi C, Paolisso G. Insulin/IGF-Isignaling pathway: an evolutionarily conserved mechanism of longevity from yeast to humans. Am J Physiol Endocrinol Metab. Nov 2003; 285(5):E1064-E1071.

55. Kaletsky R, Murphy CT. The role of insulin/IGF-like signaling in C. elegans longevity and aging. Dis Model Mech. Jul 2010;3(7-8) 415-419.

56. Vanfleteren JR, Braeckman BP. Mechanisms of life span determination in Caenorhabditis elegans. Neurobiol Aging. Sep 1999;20(5): 487-502.

57. Honda Y, Honda S. The daf-2 gene network for longevity regulates oxidative stress resistance and Mn-superoxide dismutase gene expression in Caenorhabditis elegans. FASEB J. Aug 1999;13(11):1385-1393.

58. Scott BA, Avidan MS, Crowder CM. Regulation of hypoxic death in C. elegans by the insulin/IGF receptor homolog DAF-2. Science. June 28, 2002;296(5577):2388-2391.

59. Garsin DA, Villanueva JM, Begun J, et al. Long-lived C. elegans daf-2 mutants are resistant to bacterial pathogens. Science. June 20, 2003;300(5627):1921.

60. Tullet JM, Hertweck M, An JH, et al. Direct inhibition of the longevitypromoting factor SKN-1 by insulin-like signaling in C. elegans. Cell March 21, 2008;132(6):1025-1038.

61. Hsieh CC, DeFord JH, Flurkey K, Harrison DE, Papaconstantinou J. Implications for the insulin signaling pathway in Snell dwarf mouse longevity: a similarity with the C. elegans longevity paradigm. Mech Ageing Dev. May 2002;123(9):1229-1244.

62. Ziv E, Hu D. Genetic variation in insulin/IGF-1 signaling pathways and longevity. Ageing Res Rev. Apr 2011;10(2):201-204.

63. Mercado N, Thimmulappa R, Thomas CM, et al. Decreased histone deacetylase 2 impairs Nrf2 activation by oxidative stress. Biochem Biophys Res Commun. March 11, 2011;406(2):292-298.

64. Osoata GO, Yamamura S, Ito M, et al. Nitration of distinct tyrosine residues causes inactivation of histone deacetylase 2. Biochem Biophys Res Commun. July 3, 2009;384(3):366-371.

65. Izmaylov DM, Obukhova LK. Geroprotector effectiveness of melatonin: investigation of lifespan of Drosophila melanogaster. Mech Ageing Dev. January 15, 1999;106(3):233-240.

66. Bulterijs S. Metformin as a geroprotector. Rejuvenation Res. Oct 2011; 14(5):469-482.

67. Anisimov VN, Berstein LM, Popovich IG, et al. If started early in life, metformin treatment increases life span and postpones tumors in female SHR mice. Aging (Albany NY). Feb 2011;3(2):148-157.

68. Anisimov VN, Berstein LM, Egormin PA, et al. Effect of metformin on life span and on the development of spontaneous mammary tumors in HER-2/neu transgenic mice. Exp Gerontol. Aug 2005;40(8-9): 685-693.

69. Wang S, Song P, Zou MH. AMP-activated protein kinase, stress responses and cardiovascular diseases. Clin Sci (Lond). June 1, 2012; 122(12):555-573.
70. Canto C, Gerhart-Hines Z, Feige JN, et al. AMPK regulates energy expenditure by modulating NAD+ metabolism and SIRT1 activity. Nature. April 23, 2009;458(7241):1056-1060.

71. Dowling RJ, Zakikhani M, Fantus IG, Pollak M, Sonenberg N. Metformin inhibits mammalian target of rapamycin-dependent translation initiation in breast cancer cells. Cancer Res. November 15, 2007;67(22): 10804-10812.

72. Memmott RM, Mercado JR, Maier CR, Kawabata S, Fox SD, Dennis PA. Metformin prevents tobacco carcinogen - induced lung tumorigenesis. Cancer Prev Res (Phila). Sep 2010;3(9):1066-1076.

73. Lai SW, Liao KF, Chen PC, Tsai PY, Hsieh DP, Chen CC. Antidiabetes drugs correlate with decreased risk of lung cancer: a populationbased observation in Taiwan. Clin Lung Cancer. Mar 2012;13(2): 143-148.

74. van der MT. Co-morbidities of COPD in primary care: frequency, relation to COPD, and treatment consequences. Prim Care Respir J. Dec 2010;19(4):326-334

75. Poeggeler B, Saarela S, Reiter RJ, et al. Melatonin - a highly potent endogenous radical scavenger and electron donor: new aspects of the oxidation chemistry of this indole accessed in vitro. Ann NY Acad Sci. November 17, 1994;738:419-420.

76. Anisimov VN, Zavarzina NY, Zabezhinski MA, et al. Melatonin increases both life span and tumor incidence in female CBA mice. J Gerontol A Biol Sci Med Sci. Jul 2001;56(7):B311-B323.

77. Anisimov VN, Alimova IN, Baturin DA, et al. Dose-dependent effect of melatonin on life span and spontaneous tumor incidence in female SHR mice. Exp Gerontol. Apr 2003;38(4):449-461.

78. Sharman EH, Sharman KG, Ge YW, Lahiri DK, Bondy SC. Age-related changes in murine CNS mRNA gene expression are modulated by dietary melatonin. J Pineal Res. Apr 2004;36(3):165-170.

79. Anisimov VN, Popovich IG, Zabezhinski MA, Anisimov SV, Vesnushkin GM, Vinogradova IA. Melatonin as antioxidant, geroprotector and anticarcinogen. Biochim Biophys Acta. May 2006;1757(5-6): 573-589.

80. Gumral N, Naziroglu M, Ongel K, et al. Antioxidant enzymes and melatonin levels in patients with bronchial asthma and chronic obstructive pulmonary disease during stable and exacerbation periods. Cell Biochem Funct. Jul 2009;27(5):276-283.

81. de Matos Cavalcante AG, de Bruin PFC, de Bruin VMS, et al. Melatonin reduces lung oxidative stress in patients with chronic obstrutive pulmonary disease: a randomized, double-blind, placebo-controlled study. Journal of Pineal Research. 2012;no.

82. Rodella LF, Favero G, Rossini C, et al. Aging and vascular dysfunction: beneficial melatonin effects. Age (Dordr). November 23, 2011.

83. Kim GD, Lee SE, Kim TH, Jin YH, Park YS, Park CS. Melatonin suppresses acrolein-induced IL-8 production in human pulmonary fibroblasts. J Pineal Res. Apr 2012;52(3):356-364.

84. Mishra A, Paul S, Swarnakar S. Downregulation of matrix metalloproteinase- 9 by melatonin during prevention of alcohol-induced liver injury in mice. Biochimie. May 2011;93(5):854-866.

85. de la Lastra CA, Villegas I. Resveratrol as an antioxidant and prooxidant agent: mechanisms and clinical implications. Biochem Soc Trans. Nov 2007;35(Pt 5):1156-1160.

86. Knutson MD, Leeuwenburgh C. Resveratrol and novel potent activators of SIRT1: effects on aging and age-related diseases. Nutr Rev. Oct 2008;66(10):591-596.

87. Frojdo S, Cozzone D, Vidal H, Pirola L. Resveratrol is a class IA phosphoinositide 3-kinase inhibitor. Biochem J. September 15, 2007 ; 406(3):511-518

88. Centeno-Baez C, Dallaire P, Marette A. Resveratrol inhibition of inducible nitric oxide synthase in skeletal muscle involves AMPK but not SIRT1. Am J Physiol Endocrinol Metab. Nov 2011;301(5): E922-E930.

89. Donnelly LE, Newton R, Kennedy GE, et al. Anti-inflammatory effects of resveratrol in lung epithelial cells: molecular mechanisms. Am J Physiol Lung Cell Mol Physiol. Oct 2004;287(4):L774-L783. 
90. Babar P, Adamson C, Walker GA, Walker DW, Lithgow GJ. P13-kinase inhibition induces dauer formation, thermotolerance and longevity in C. elegans. Neurobiol Aging. Sep 1999;20(5):513-519.

91. Moskalev AA, Shaposhnikov MV. Longevity extension by specific inhibition of pI3K in Drosophila melanogaster. Adv Gerontol. 2008; 21(4):602-606.

92. To Y, Ito K, Kizawa Y, et al. Targeting Phosphoinositide-3-kinase- $\{$ delta $\}$ with Theophylline Reverses Corticosteroid Insensitivity COPD. Am J Respir Crit Care Med. March 11, 2010.

93. Moonen HJ, Geraets L, Vaarhorst A, Bast A, Wouters EF, Hageman GJ. Theophylline prevents NAD+ depletion via PARP-1 inhibition in human pulmonary epithelial cells. Biochem Biophys Res Commun. December 30, 2005;338(4):1805-1810.

94. Bjedov I, Partridge L. A longer and healthier life with TOR downregulation: genetics and drugs. Biochem Soc Trans. Apr 2011;39(2): $460-465$.

95. Morselli E, Maiuri MC, Markaki M, et al. The life span-prolonging effect of sirtuin-1 is mediated by autophagy. Autophagy. Jan 2010; 6(1):186-188.
96. Lee JS, Park KY, Min HG, et al. Negative regulation of stress-induced matrix metalloproteinase-9 by Sirt1 in skin tissue. Exp Dermatol. Dec 2010;19(12):1060-1066.

97. Borra MT, Smith BC, Denu JM. Mechanism of human SIRT1 activation by resveratrol. J Biol Chem. April 29, 2005;280(17): 17187-17195.

98. Milne JC, Lambert PD, Schenk S, et al. Small molecule activators of SIRT1 as therapeutics for the treatment of type 2 diabetes. Nature. November 29, 2007;450(7170):712-716.

99. Lee JS, Surh YJ. Nrf2 as a novel molecular target for chemoprevention. Cancer Lett. June 28, 2005;224(2):171-184.

100. Mukherjee S, Gangopadhyay H, Das DK. Broccoli: a unique vegetable that protects mammalian hearts through the redox cycling of the thioredoxin superfamily. J Agric Food Chem. January 23, 2008;56(2): 609-617.

101. Malhotra D, Thimmulappa RK, Mercado N, et al. Denitrosylation of HDAC2 by targeting Nrf2 restores glucocorticosteroid sensitivity in macrophages from COPD patients. J Clin Invest. Nov 2011; 121(11):4289-4302.

\section{Publish your work in this journal}

The International Journal of COPD is an international, peer-reviewed journal of therapeutics and pharmacology focusing on concise rapid reporting of clinical studies and reviews in COPD. Special focus is given to the pathophysiological processes underlying the disease, intervention programs, patient focused education, and self management protocols.

\section{Dovepress}

This journal is indexed on PubMed Central, MedLine and CAS. The manuscript management system is completely online and includes a very quick and fair peer-review system, which is all easy to use. Visit http://www.dovepress.com/testimonials.php to read real quotes from published authors. 